Tropical Journal of Pharmaceutical Research February 2019; 18 (2): 415-419

ISSN: $1596-5996$ (print); 1596-9827 (electronic)

(c) Pharmacotherapy Group, Faculty of Pharmacy, University of Benin, Benin City, 300001 Nigeria.

\title{
Combined effect of dydrogesterone and letrozole on humoral immune function, sex hormone levels and serology-related indices in patients with endometriosis
}

\author{
Dacheng Qu, Xiaoping Huang*, Yamei Yang \\ Department of Obstetrics and Gynecology, Affiliated Hospital of North Sichuan Medical College, Nanchong City, China
}

*For correspondence: Email: wuxiaoyankjdj@163.com; Tel: +86-712-2778100

Sent for review: 13 November 2018

Revised accepted: 23 January 2019

\begin{abstract}
Purpose: To investigate the combined effect of dydrogesterone and letrozole on humoral immunity, and levels of sex hormones and serology-related indices in patients with endometriosis.

Methods: Patients with endometriosis (98 cases) were randomly assigned to two groups of 49 patients each: control group and study group. The control group received dydrogesterone $(10 \mathrm{mg} / \mathrm{kg}$ ) orally from the fifth day to the twenty-fifth day of the patient's menstrual cycle, twice daily; while the study group, in addition to dydrogesterone $(10 \mathrm{mg} / \mathrm{kg})$, received letrozole $(2.5 \mathrm{mg} / \mathrm{kg})$. Treatment in both groups lasted one month, and changes in the levels of humoral immunity, sex hormones and serology-related indices were evaluated before and after treatment. Clinical effectiveness and adverse reactions in both groups were also assessed.

Results: After treatment, total effectiveness was markedly higher in the study group (91.84 \%) than in control group (77.55\%, $p<0.05)$. Post-treatment, humoral immunity (IgM, IgG and C3) levels were significantly higher in the study group than in control group $(p<0.05)$ while estradiol $(E 2)$ level in both groups were significantly reduced; however, E2 level was markedly lower in the study group than in control group $(p<0.05)$.

Conclusion: These results suggest that the combination of dydrogesterone with letrozole alleviates clinical symptoms of endometriosis, improves humoral immune function, and maintains sex hormone levels.
\end{abstract}

Keywords: Endometriosis, Dydrogesterone, Letrozole, Humoral immunity, Sex hormones, Serologicalrelated indices

This is an Open Access article that uses a funding model which does not charge readers or their institutions for access and distributed under the terms of the Creative Commons Attribution License (http://creativecommons.org/licenses/by/4.0) and the Budapest Open Access Initiative (http://www.budapestopenaccessinitiative.org/read), which permit unrestricted use, distribution, and reproduction in any medium, provided the original work is properly credited.

Tropical Journal of Pharmaceutical Research is indexed by Science Citation Index (SciSearch), Scopus, International Pharmaceutical Abstract, Chemical Abstracts, Embase, Index Copernicus, EBSCO, African Index Medicus, JournalSeek, Journal Citation Reports/Science Edition, Directory of Open Access Journals (DOAJ), African Journal Online, Bioline International, Open-J-Gate and Pharmacy Abstracts

\section{INTRODUCTION}

Endometriosis is a medical condition in women caused by the growth of endometrial tissue outside the uterine cavity. Women of childbearing age are at increased risk of this disease which manifests mainly as dysmenorrhea, dyspareunia, chronic pelvic pain, attachments, and infertility [1,2]. Surgery and use of drugs are the major treatment options for endometriosis. However, they only serve as mere palliatives. Moreover, surgery may damage abdominal organs such as the bladder, and it cannot sufficiently prevent recurrence of the disease. 
Dydrogesterone prevents intimal hyperplasia and carcinogenesis caused by estrogens [3], while letrozole inhibits the synthesis of estrogen and increases the secretion of gonadotropin in a bid to promote rapid development of follicles [4]. The aim of this study was to investigate the influence of combination of dydrogesterone and letrozole on humoral immune function, levels of sex hormones and serology-related indices in patients with endometriosis.

\section{METHODS}

\section{Clinical profile of patients}

Patients with endometriosis (98 cases) who were seen for a period spanning more than 2 years were used as subjects. They were randomly assigned to control group and study group (49 patients per group). The study group patients were aged 20 to 38 years (mean age $=30.32 \pm$ 3.59 years), and the course of disease ranged from 1 to 7 years. They were staged in line with the American Fertility Association (AFS) classification of endometriosis thus: stage I (8 cases), stage II (14 cases), stage III (14 cases), and stage IV (13 cases). Patients in the control group were aged 20 to 39 years (mean age $=$ $32.25 \pm 5.62$ years), and the course of disease ranged from 1 to 7 years. They were staged according to AFS classification as follows: stage I (9 cases), stage II (15 cases), stage III (13 cases), and stage IV (12 cases).

The inclusion criteria were: (1) patients who met the Diagnostic and Therapeutic Criteria for Endometriosis [5]; (2) patients aged 18 to 50 years; (3) patients who did not receive treatment that could potentially affect the outcomes of the study; (4) patients who had no severe liver and kidney diseases, or history of drug allergy and mental illnesses; (5) patients who were not pregnant or lactating; and (6) patients who signed written informed consent with their family members. The exclusion criteria were: (1) patients with severe liver and kidney dysfunctions; (2) patients with severe mental or neurological disorders; (3) pregnant and lactating patients, and (4) patients who did not comply with the study protocol. Age and AFS stages were comparable for both groups.

This research also received approval from the Ethical Committee of Department of Obstetrics and Gynecology, Affiliated Hospital of North Sichuan Medical College (approval no. 20188318), and was carried out in line with the Helsinki Declaration of 1964 , as amended in 1996 [6].

\section{Treatment regimen}

\section{Control group}

Dydrogesterone $(10 \quad \mathrm{mg} / \mathrm{kg})$ was orally administered from the fifth day to the twenty-fifth day of the patient's menstrual cycle, twice daily.

\section{Study group}

In addition to dydrogesterone (10 $\mathrm{mg} / \mathrm{kg})$, letrozole (2.5 mg/kg/day) was administered. Treatment in both groups lasted one month.

\section{Assessment of treatment indices}

\section{Clinical effectiveness}

Clinical effectiveness was evaluated based on the Guidelines for Clinical Research on New Drugs in Traditional Chinese Medicine [7], and classified into three categories: remarkably effective, effective and ineffective as explained hereunder:

Effective: The symptoms were significantly improved relative to before treatment.

Ineffective: The symptoms did not improve, when compared with those before treatment.

The total effectiveness was calculated as in Eq 1.

$\mathrm{TE}=\{(\mathrm{RE}+$ effective $) / T N C \times 100 \ldots \ldots(1)$

where TE is total effectiveness, RE is remarkably effective, $E$ is effective and TNC is total number of cases.

\section{Humoral immune function}

Changes in the levels of $\lg M, \lg G, \lg A$, and C3 before and after treatment were measured using automated protein analyzer.

\section{Sex hormones}

The levels of $\mathrm{FSH}, \mathrm{LH}$ and E2, before and after treatment were measured using radioimmunoassay.

\section{Serology-related indices}

The levels of IL-6, TNF- $\alpha$, and VEGF were assayed using ELISA kits as per the manufacturer's protocol, while CA125 was determined using chemiluminescence analyzer. 


\section{Statistical analysis}

The results are presented as mean \pm SEM. Group comparison was done with Student $t$-test and Chi-square test. All statistical analyses were carried out with SPSS version 17. Statistical significance was fixed at $p<0.05$.

\section{RESULTS}

\section{Clinical effectiveness}

Table 1 shows that total effectiveness was significantly higher in the study group $(91.84 \%)$ than in control $(77.55 \%, p<0.05)$.

\section{Humoral immune function}

Table 2 shows that pre-treatment values of IgM, $\lg$, IgA and C3 were comparable in both groups $(p>0.05)$. However, study group post-treatment levels of $\operatorname{lgM}$, IgG and C3 were significantly

Table 1: Clinical effectiveness in the two groups (n, \%) higher than the corresponding control values $(p<$ $0.05)$. Values of IgA were comparable between the two groups $(p>0.05)$.

\section{Effect of treatment on sex hormones}

As shown in Table 3, pre- and post-treatment levels of FSH and LH were comparable between both groups $(p>0.05)$. However, there were marked post-treatment reductions in E2 levels in both groups, but E2 was markedly less in the study group than in control $(p<0.05)$.

\section{Serology-related indices}

There were significant reductions in IL-6, TNF- $\alpha$, VEGF and CA125 in the two groups after treatment, when compared to values before treatment, but the degree of reduction was higher in the study group than in control group $(p<$ 0.05; Table 4).

\begin{tabular}{|c|c|c|c|c|c|}
\hline Group & $\mathbf{n}$ & Remarkably effective & Effective & Ineffective & Total effectiveness \\
\hline Control & 49 & $15(30.61)$ & $23(46.94)$ & $11(22.45)$ & $38(77.55)$ \\
\hline Study & 49 & $20(40.82)$ & $25(51.02)$ & $4(8.16)$ & $45(91.84)$ \\
\hline$x^{2}$ & & & & & 3.241 \\
\hline$P$ & & & & & 0.015 \\
\hline
\end{tabular}

Table 2: Levels of humoral immune function $(n=49)$

\begin{tabular}{ccccc}
\hline \multirow{2}{*}{ Parameter } & \multicolumn{2}{c}{ Study group } & \multicolumn{2}{c}{ Control Group } \\
\cline { 2 - 5 } & Before treatment & After treatment & Before treatment & After treatment \\
\hline $\lg M(\mathrm{~g} / \mathrm{L})$ & $0.15 \pm 0.11$ & $0.43 \pm 0.13^{\#}$ & $0.19 \pm 0.16$ & $0.71 \pm 0.16$ \\
$\lg A(\mathrm{~g} / \mathrm{L})$ & $0.76 \pm 0.21$ & $0.84 \pm 0.23$ & $0.82 \pm 0.27$ & $0.83 \pm 0.25$ \\
$\operatorname{lgG}(\mathrm{g} / \mathrm{L})$ & $0.28 \pm 0.12$ & $0.53 \pm 0.11^{* \#}$ & $0.26 \pm 0.12$ & $0.87 \pm 0.19^{*}$ \\
$\mathrm{C} 3(\mathrm{~g} / \mathrm{L})$ & $1.14 \pm 0.27$ & $0.75 \pm 0.17^{\#}$ & $1.20 \pm 0.25$ & $0.35 \pm 0.11^{*}$ \\
\hline
\end{tabular}

${ }^{\star} P<0.05$, relative to value before treatment; ${ }^{\#} p<0.05$, relative to control

Table 3: LH and FSH levels in the patients

\begin{tabular}{ccccc}
\hline \multirow{2}{*}{ Parameter } & \multicolumn{2}{c}{ Study group } & \multicolumn{2}{c}{ Control group } \\
\cline { 2 - 4 } & Pre-treatment & Post-treatment & Pre- treatment & Post- treatment \\
\hline FSH $(\mathrm{IU} / \mathrm{ml})$ & $4.74 \pm 1.36$ & $4.71 \pm 1.21$ & $4.77 \pm 1.34$ & $4.76 \pm 1.25$ \\
LH $(\mathrm{IU} / \mathrm{L})$ & $6.75 \pm 1.31$ & $6.44 \pm 0.35$ & $6.73 \pm 1.27$ & $6.42 \pm 1.42$ \\
E2 $(\mathrm{pmol} / \mathrm{L})$ & $256.75 \pm 13.81$ & $137.61 \pm 11.47^{* \#}$ & $256.81 \pm 1.85$ & $155.38 \pm 11.71^{*}$ \\
\hline${ }^{*} p<0.05$, relative to value before treatment; ${ }^{*} p<0.05$, relative to control
\end{tabular}

${ }^{*} p<0.05$, relative to value before treatment; ${ }^{\#} p<0.05$, relative to control

Table 4: Levels of IL-6, TNF-a, VEGF and CA125 $(n=49)$

\begin{tabular}{lcccc}
\hline \multirow{2}{*}{ Parameter } & \multicolumn{2}{c}{ Study group } & \multicolumn{2}{c}{ Control group } \\
\cline { 2 - 5 } & Before treatment & After treatment & Before treatment & After treatment \\
\hline IL-6 $(\mathrm{ng} / \mathrm{L})$ & $27.12 \pm 6.51$ & $14.67 \pm 3.61$ & $27.44 \pm 5.35$ & $18.75 \pm 0.48$ \\
TNF- $\alpha(\mathrm{ng} / \mathrm{L})$ & $32.13 \pm 7.22$ & $18.63 \pm 2.97$ & $31.87 \pm 7.03$ & $23.22 \pm 4.56$ \\
VEGF $(\mathrm{pmol} / \mathrm{ml})$ & $187.81 \pm 17.47^{*}$ & $98.52 \pm 11.55^{\pi}$ & $187.78 \pm 17.52^{*}$ & $125.52 \pm 11.75^{*}$ \\
CA125 (U/L) & $43.76 \pm 8.28^{*}$ & $13.2 \pm 4.23^{*}$ & $43.83 \pm 8.32^{*}$ & $22.85 \pm 4.38^{*}$ \\
\hline
\end{tabular}

$P<0.05$, relative to the value before treatment; ${ }^{\#} p<0.05$, relative to control group 
Table 5: Incidence of adverse reactions ( $\mathrm{n}, \%)$

\begin{tabular}{lcccccc}
\hline Group & $\mathbf{n}$ & Hemorrhoids & $\begin{array}{c}\text { Vaginal } \\
\text { dryness }\end{array}$ & $\begin{array}{c}\text { Vaginal } \\
\text { bleeding }\end{array}$ & Edema & Total incidence \\
\hline Study & 49 & $1(2.04)$ & $2(4.08)$ & $6(12.24)$ & $1(2.04)$ & $10(20.41)$ \\
Control & 49 & $9(18.37)$ & $10(20.41)$ & $5(10.20)$ & $3(6.12)$ & $27(55.10)$ \\
\hline
\end{tabular}

$P<0.05$, when compared to control group

\section{Adverse reactions}

Table 5 reveals that during the treatment, the main adverse reactions in both groups were hemorrhoids, vaginal dryness, edema and vaginal bleeding. There were less complications of hemorrhoids and vaginal dryness in the study group than in control $(p<0.05)$, but vaginal bleeding and edema were comparable between both groups $(p>0.05)$. Total incidents of adverse reactions were markedly lower in the study group $(20.41 \%)$ than in control group $(55.10 \%)(p<$ $0.05)$.

\section{DISCUSSION}

Endometriosis is an estrogen-dependent disease characterized by proliferation of endometrial cells, invasion, and rapid recurrence. Although it is a benign disease, it may become resistant to treatment due to distant metastasis and development of malignancy [8]. Studies have shown that endometriosis is caused by changes in uterine location, abnormal reproductive system, excessive secretion of estrogens from endometrial tissue, abnormal proliferation of endometrial cells, and high expression of aromatase in the endometrium [9].

Dydrogesterone is an oral progesterone that inhibits the secretion of hypothalamic and pituitary gonadotropins, stimulates the endometrium to enter complete secretory phase, and reduces the risk of endometrial cell proliferation and cancer caused by estrogen. It exerts no deleterious effect on lipid metabolism and normal intima, while promoting contraction of damaged endometrium [9]. In addition, it does not exert inhibitory effect on ovulation in patients with endometriosis, and it has no influence on their pregnancy demands [10]. Letrozole is a third-generation, highly selective aromatase inhibitor that reduces pain in patients with endometriosis. It inhibits the activity of aromatase by competing with the endogenous substrate for the enzyme active site, thereby blocking the conversion of androgens to estrogens in ovarian and extra-ovarian tissues [11]. Letrozole also promotes the development of follicles and ovulation.

In this study, the study group had higher total effectiveness than the control group. The total incidents of adverse reactions were significantly lower in the observation group than in control group. These results suggest that the combination of dydrogesterone with letrozole may be safe and effective in improving the clinical symptoms of endometriosis.

Despite intense research into the etiology of endometriosis, its pathogenesis is still not fully elucidated. Several studies have shown that the disease is closely associated with the state of the patient's immunity [12]. Immunoglobulin A ( $\lg A)$ is divided into serotypes which are secreted according to their immune function. Secretory $\lg A$ is the main anti-infective immune antibody in the mucosa. Immunoglobulin G ( $\lg G)$, the main antibody produced in humoral immune response, is a four-chain monomer and the most important antibody component in serum and extracellular fluid. Immunoglobulin M (IgM), the first antibody secreted in the immune response, provides primary defense against infections, and can be used as an early diagnostic indicator of preparedness of the human body against infections. Complement C3, synthesized by phagocytic cells and liver, is normally elevated in serum, and often used as an auxiliary indicator for early diagnosis of some acute inflammatory or infectious diseases.

In this study, the pre-treatment values of $\operatorname{lgM}$, $\lg \mathrm{G}, \lg \mathrm{A}$ and $\mathrm{C} 3$ were similar in the two groups. However, the post-treatment levels of $\operatorname{lgM}$, IgG and C3 were markedly higher in the study group than in the control group. Pre- and posttreatment levels of $\lg \mathrm{A}$, FSH and $\mathrm{LH}$ did not differ appreciably between the two groups, but posttreatment E2 was significantly lower in the study group. By mediating immune-inflammatory reactions, IL-6 causes local pelvic fibrosis and adhesion, and aggravates cytotoxicity, thereby promoting the development of clinical symptoms seen in endometrial women [13]. Studies have shown that TNF- $\alpha$ is associated with dysregulation of cytokines, and is highly expressed in endometriosis [14]. Moreover, VEGF is a crucial pro-angiogenic molecule which promotes the growth of endometrium, and its level in ectopic endometrial tissue is normally higher than in normal tissue [15]. CA125 is a special membrane antigen synthesized during the conversion of normal cells to malignant cells during induction of mutations in glycoproteins. As a marker of ovarian cancer, it is expressed 
mainly in epithelial cells of embryonic body cavity [16]. In this study, after treatment, the levels of IL-6, TNF- $\alpha$, VEGF and CA125 in the two groups were significantly reduced when compared to their corresponding levels before treatment, but were markedly less in the study subjects than in controls.

\section{Limitations of the study}

The likely limitations in this study include: (1) short follow-up period, and (2) the use of small sample size and a single race/population

\section{CONCLUSION}

This study has demonstrated that the combination of dydrogesterone with letrozole effectively alleviates clinical symptoms of endometriosis, improves humoral immune function, and maintains the levels of sex hormones. This combination therapy may be therefore be considered for the management of endometriosis.

\section{DECLARATIONS}

\section{Conflict of Interest}

No conflict of interest associated with this work.

\section{Contribution of Authors}

We declare that this work was done by the author(s) named in this article and all liabilities pertaining to claims relating to the content of this article will be borne by the authors. All authors read and approved the manuscript for publication. Xiaoping Huang conceived and designed the study. Dacheng Qu, Xiaoping Huang, Yamei Yang collected and analyzed the data, while Dacheng Qu wrote the manuscript.

\section{REFERENCES}

1. Zhang YY, Li L, Xue J, Bai CY, Feng HL. Clinical research on effects of mifepristone combined with xiaojin capsule in the treatment of endometriosis. World Chin Med 2017; 12(9): 2047-2049.

2. Wang Y, Song SF. Study of Different Doses of Letrozole and Medroxyprogesterone Acetate Co-treating Endometriotic Rats. J Pract Obstetr Gynecol 2018; (2): 126-131.
3. Luo YH. Effect of dydrogesterone on serum CA125 in patients with endometriosis. Shanxi Med J 2017; 46(3): 402-404.

4. Li XM, He CN, Wu D, Wu FQ. Therapeutic effects of dydrogesterone and gestrenene on endometriosis after operation. Clin Med China 2015; 22(3): 269-272.

5. Ma HS, Pan HY, Han XR, Zhen LC. Effect of letrozole on endometriosis and observation on the effect of serum CA125. People's Mil Surgeon 2016; 23(8): 823-824.

6. World Health Organization. Declaration of Helsinki. $\mathrm{Br}$ Med J 1996; 313(7070): 1448-1449.

7. Liu BL. Interpretation and Drafting Instructions of General Guidelines of Clinical Trials on New Drugs of Traditional Chinese Medicine (TCM). World Sci TechnologyModernization Tradit Chin Med 2016; 18(12): 2075-2081

8. Wu $Y Z$, Fang $X M$. Curative effect of triptorelin and gestrinone on the prevention of postoperative reoccurrence of endometriosis. Chin J Human Sex 2014; 12(6): 22-24.

9. Liu J. Clinical observation of dedrogesterone and progesterone in the treatment of postoperative endometriosis. Maternal Child Health Care China 2016; 31(1): 197-199.

10. Tian W, Wu M, Deng Y. Comparison of Changes in the Lipid Profiles of Eastern Chinese Postmenopausal Women with Early-Stage Breast Cancer Treated with Different Aromatase Inhibitors: A Retrospective Study. Clin Pharmacol Drug Dev 2017; 7(8): 837-843.

11. Abo-Touk NA, Sakr HA, Abd EA. Switching to letrozole versus continued tamoxifen therapy in treatment of postmenopausal women with early breast cancer. J Egypt Natl Canc Inst 2010; 22(1): 79-85.

12. Goshtasebi A, Nematollahzadeh M, Hariri FZ, Montazeri $A$. The short form endometriosis health profile (EHP-5): translation and validation study of the Iranian version. $J$ Ovarian Res 2011; 4(1): 11.

13. Demir M, Ince O, Ozkan B, Kelekci S, Sutcu R, Yilmaz B. Endometrial flushing $\alpha \vee \beta 3$ integrin, glycodelin and PGF2a levels for evaluating endometrial receptivity in women with polycystic ovary syndrome, myoma uteri and endometrioma. Gynecol Endocrinol 2017; 33(9): 716-720.

14. Liang RN, Shi M, Zhan SY, Chen Z, Li PS, Sun $X Y$. Effect of Ping Chong Jiang Ni Recipe on Apoptosis and Expressions of TNF- $\alpha$ and IL-8 in Nude Endometriosis Model Mice. Chin J Integr Tradit West Med 2017; 37(8): 979-984.

15. Peng GT. Study on the expression levels of serum CA125 and CA199 in 150 patients with endometriosis complicated with severe intestinal adhesion. J Today Health 2016; 15(11): 143.

16. Zhai K. Diagnostic value of combined detection of serum CA125 and CA199 for endometriosis. Henan J Surg 2018; (1): 75-76. 